\title{
Susceptibilidade de bovinos mestiços ao carrapato Boophilus microplus (Canestrini, 1887) na microregião Fluminense do Grande Rio, Estado do Rio de Janeiro
}

\author{
Susceptibility of Zebu X European crossbred cattle to Boophilus \\ microplus (Canestrini, 1887) in the region Fluminense do Grande Rio, State \\ of Rio de Janeiro
}

\author{
Luis Felipe Castro Graeff Vianna ${ }^{1}$,João Luiz Horácio Faccini ${ }^{2}$ e Mauricio Balesteiro Pereira ${ }^{3}$
}

\begin{abstract}
Resumo
Vinte e quatro bezerros mestiços de Bos indicus $X$ B. taurus, com aproximadamente nove meses de idade, foram distribuídos em três grupos. Grupo I, composto por 18 animais com características fenotípicas consagradas do zebu (presença de cupim, barbela, pregas prepuciais ou vulvares longas, pele fina e frouxa). O grupo II foi constituído por seis animais também azebuados, entretanto, com as características acima mencionadas, incompletas e o grupo III, foi considerado como a reunião (24 animais) dos dois grupos. Sem prejuízo desta classificação, os animais foram alojados em três piquetes. Em cada lote, ficaram oito animais (seis do grupo I e dois do grupo II). Durante o período experimental, ou seja, de set/88 a ago/89, não foi realizada qualquer infestação artificial dos animais. A cada 14 dias, eram contadas, de todo o hemisfério direito de cada animal. as fêmeas ingurgitadas de Boophilus microplus com tamànho superior a $4,5 \mathrm{~mm}$. $O$ B. microplus esteve presente durante todo o período, contudo, o grau de infestação nọs animais foi maior entre maio e setembro. Os bovinos do grupo II tiveram uma quantidade significativamente maior de $B$. microplus do que os animais do grupo I.
\end{abstract}

Palavras-chave: carrapato, Boophilus microplus, bovino, zebu

\section{Introdução}

Nos últimos 30 anos, foram desenvolvidos muitos trabathos relacionados à mensuração e herdabilidade da resistência para o Boophilus microplus, tanto em bovinos mestiços como em puros (Penna, 1990). Os resultados dessas pesquisas, indicaram claramente, que a utilização da resis- tência é um dos aspectos promissores no controle integrado do B. microplus, principalmente em países de clima tropical. No entanto, há de se levar em consideração, que a resistência ao $B$. microplus pode ser alterada em função de diversos fatores, incluindo aqueles de ordem fisiológica, nutricional e climática (Sutherst et al., 1988).

$O$ objetivo deste trabalho, foi avaliar a resistência de animais mestiços de Bos indicus e $B$. taurus frente ao $B$. microplus, nas condições climáticas e de manejo utilizados por criadores na microregião Fluminense do Grande Rio, Estado do Rio de Janeiro.

\section{Material e Métodos}

O experimento foi realizado na Universidade Federal Rural do Rio de Janeiro (UFRRJ), localizada no Município de Itaguaí, com as seguintes coordenadas: LAT. $22^{\circ} 45^{\prime}$ S, Long. $43^{\circ} 41^{\prime} \mathrm{W}$, Alt. 30m, com precipitação pluviométrica anual média de $1326 \mathrm{~mm}$ e média mensal de $110 \mathrm{~mm}$. O período de maior precipitação, tem sido de dezembro a abril. A temperatura média anual é de $24,1^{\circ} \mathrm{C}$ e o período frio, de maio a agosto.

Foram adquiridos 24 bezerros mestiços de Bos indicus $X B$. taurus, com média de nove meses de idade, nascidos em fazendas circunvizinhas à área da UFRRJ.

$\mathrm{Na}$ aquisição, procurou-se animais semelhantes àqueles bovinos típicos da região, provenientes do cruzamento natural e sucessivo de animais $B$. indicus $\times B$. taurus, consagrados entre os criadores da região, como resistentes ao carrapato, a despeito de sua baixa produtividade. Todos os animais empregados no experimento, eram mestiços de zebu, contudo, a fim de se verificar a influência da mestiça-

\footnotetext{
1 Prof. Titular, D.M.C

2 Prof. Titular D.P.A.

3 Prof. Adjunto, D.G., UFRRJ, Km 47 antiga Rio-S.Paulo, Seropédica. Itaguaí, CEP 23851-970, RJ, Brasil.
} 
gem na maior ou menor resistência ao carrapato B. microplus, os animais foram divididos em dois grupos: o grupo I foi composto por 18 animais com características fenotípicas do zebu (presença de barbela, cupim, orelhas e pregas prepuciais e vulvais longas) e grupo II composto por seis animais, também azebuados, mas com algumas características fenotípicas ainda do $B$. taurus (ausência parcial dos caracteres citados anteriormente para zebu). Objetivando uma perspectiva global das variáveis, para as análises estatíscas, foi considerado como conjunto, a reunião dos dois grupos de animais (grupo III).

Seguindo a classificação zootécnica, os animais foram divididos em três lotes de oito bovinos cada, procurando-se uniformizar os lotes, de acordo com a mestiçagem dos animais, de tal modo, que todos os três lotes tivessem o mesmo número de animais com as mesmas características fenotípicas. Foram então distribuídos em três piquetes com 6,2 hectares, compostos principalmente por capim rabode-burro (Cynodon dactylon), grama batatais (Paspalum notatum) e capim colonião (Panicum maximum). Estes piquetes foram previamente utilizados por outros bovinos parasitados por carrapatos.

As populações de larvas de B. microplus nos piquetes, foram aquelas que já estavam presentes antes do início do experimento. Os bovinos estavam livres de carrapatos antes de ingressarem em seus piquetes e não foi realizada nenhuma infestação artificial com carrapatos, animais ou pastos. durante o período experimental.

Após um período de carência de quatro meses, a fim de se evitar uma possível influência no número de carrapatos na pastagem pela introdução dos animais, a cada interstício de 14 dias, utilizando-se um tronco de contenção, sempre iniciando-se entre 8-9 horas da manhã, eram contadas todas as fêmeas ingurgitadas de B. microplus com tamanhos entre 4,5 e 8,0mm, de todo o hemisfério direito de cada animal e posteriormente multiplicado por dois, segundo método proposto por Wharthon \& Utech (1970)

O experimento teve a duração de 12 meses, com início em setembro de 1988 e término em agosto de 1989.

Foram calculadas as médias aritméticas do número de carrapatos, considerando-se os diferentes grupos e meses estudados. Para fins de análises de variância, os valores do número de carrapatos foram transformados em $\sqrt{ } x+0,5$.
Para a análise das diferenças entre as diversas médias, foi calculada a diferença mínima significante (DMS) pelo teste de Tukey, com probabilidade de 95\% de acerto, considerando-se a distribuição tendento à normalidade.

Foram ainda determinados o coeficiente de variação e realizado o teste $F$. As análises estatísticas foram realizadas segundo Gomes (1985).

\section{Resultados e Discussão}

As médias mensais do número de carrapatos por animal, de acordo com o grau de mestiçagem dos animais, estão expressas na Tabela 1. Foi comprovada uma diferença significativa (1\%) a favor dos animais do grupo II. Essas observações estão de acordo com dados registrados na literatura pertinente (Penna, 1990), que indicam diferenças genéticas de resistência entre taurinos e zebuínos contra o B. microplus. Bovinos com alta proporção de sangue zebu, têm sido mais resistente ao $B$. microplus do que animais de raças européias e transmitem essa característcas aos seus descendentes, numa proporção quase direta para a porcentagem de sangue zebuíno e, embora um pequeno número de meio-sangue possa ser relativamente susceptível, a maioria de zebuínos $3 / 4$ de sangue, hospedam poucos carrapatos e raramente demonstram o efeito desses parasitos (Kelley, 1943).

Porquanto, no estabelecimento de rebanhos bovinos em áreas enzoóticas para o B. microplus, como a deste experimento, é preciso considerar o grau de sangue zebu dos animais, a fim de minimizar as perdas causadas pelo carrapato. A necessidade de seleção de bovinos para a resistência ao B. microp/us, tem sido preconizada por diversos pesquisadores, dos quais citamos como exemplos Seifert (1971a) na Austrália e Madalena et al. (1985) no Brasil. Sutherst et al. (1988) estabeleceram como fator de maior importância para a resistência dos rebanhos mestiços ao $B$. microplus, a proporção de genes de B. indicus presentes. Assim sendo, os pecuaristas devem considerar sempre esta observação, antes de decidirem introduzir mais sangue europeu em seus rebanhos, com o objetivo principal de aumentar a produção de leite.

Houve uma influência significativa (1\%) da época (meses) sobre o número de carrapatos dos grupos I e III. No

Tabela 1. Média mensal do número de carrapatos por grau de mestiçagem dos animais*

\begin{tabular}{lccc}
\hline & GRUPO I & GRUPO II & GRUPO III \\
\hline Média dos valores mensais $^{\star \star}$ & $3.90 \mathrm{~b}(14.71)$ & $4.66 \mathrm{a}(21.21)$ & 4.09 \\
Coeficiente de variação (\%) & 45.89 & 51.58 & 46.24 \\
\hline
\end{tabular}

*Grupo I - animais com características fenotípicas consagradas do zebu

Grupo II - animais com características fenotípicas incompletas do zebu

Grupo III - reunião dos dois grupos acima

**Teste F com $1 \mathrm{GL}$ indicou diferença significativa a 1\%. Não há diferença significativa quando as letras que seguem as médias forem iguais

Os valores do número de carrapatos foram calculados, transformados em $\sqrt{x+0,5}$ e os valores reais encontram-se entre parênteses 
grupo II, a influência da época foi significativa ao nível de 5\% conforme se observa na Tabela 2.

Tabela 2. Resultado do teste $F$ na comparação das médias das contagens de carrapatos durante os 12 meses

(set/88 a ago/89), considerando-se o grau de mestiçagem dos animais*

\begin{tabular}{lcccc}
\hline Variável & G.L. & Grupo I & Grupo II & Grupo III \\
\hline Meses & 11 & $10.26^{\star \star \star}$ & $2.67^{\star \star}$ & $13.34^{\star \star \star}$ \\
\hline
\end{tabular}

*Grupo I - animais com características fenotípicas consagradas do zebu

Grupo II - animais com características fenotípicas incompletas do zebu

Grupo III - reunião dos dois grupos acima

**Significativo a $5 \%$

${ }^{* \star *}$ Significativo a $1 \%$

Ocorreu grande variação na distribuição do número de carrapatos em todos os três grupos (Tabela 1). O coeficiente de variação foi reflexo, tanto da variação mensal, como da variação individual, considerando-se a presença no experimento, de animais mais resistentes e menos resistentes, ocorrendo, consequentemente, uma grande variação no número de carrapatos carreados por animal. Contudo, este coeficiente de variação relativamente alto, não invalida os resultados, já que houve diferença significativa no número de carrapatos entre os dois grupos. Essa variação individual é um fato bem conhecido (Villares, 1941).

A distribuição do número de carrapatos durante os 12 meses, considerando-se diferentes grupos, está expressa na Tabela 3.

Houve uma infestação significativamente maior, por $B$. microplus em todos os animais (grupo III), durante o período frio, que correspondeu de maio a setembro. No outro período, de outubro a março, o grau de parasitismo foi nitidamente menor e o mês de abril apresentou-se como período de transição.

No grupo l, os valores foram significativamente maiores durante os meses de maio, junho, julho, agosto e setembro. Os menores valores no número de carrapatos, foram obser- vados nos meses de outubro, dezembro, janeiro e março $(\mathrm{P}<0,01)$.

No grupo II, não houve diferenças significativas na distribuição mensal de carrapatos por animal, de acordo com o teste Tukey. O teste F, mostrou diferenças significativas ao nível de 5\%. Não há uma correlação perfeita entre o teste Fe o teste Tukey, sendo este último, mais rigoroso e confiável. Os animais do grupo II, tiveram uma carga relativamente alta de carrapatos durante todo o ano de experimento, comparados com os animais do grupo I. O coeficiente de variação (Tabela 1), foi maior neste grupo, certamente em razão do menor número de animais.

Pode-se afirmar que o B. microplus esteve sempre presente durante todo o período experimental, contudo, o grau de infestação dos animais, começou a se elevar em abril, atingiu seu ápice em julho, para então declinár a partir de agosto. Durante o ano, a média de carrapatos por animal foi de 16,22, mas, em julho, época do pico de carrapatos, houve uma elevação de 2,70 vezes $(43,85)$ na média por animal. Esses números são bem próximos aos citados por Johnston (1967) em mestiços de zebu na Austrália, ao observar cargas médias de carrapatos relativamente constantes, em torno de 10 carrapatos por animal, por exame mensal, exceto de setembro a novembro, quando houve um aumento para 40 carrapatos/animal. Contudo, a carga de carrapatos observada neste experimento, poderia talvez ser menor, se os animais dispusessem de maior área de pastoreio. O aumento na taxa de lotação da pastagem, pode aumentar a população de carrapatos (Aycardi et al., 1984). Decerto, a área disponível utilizada foi bem menor do que a necessária, considerando-se o número de animais empregados no experimento.

Na Austrália, Sutherst \& Utech (1982), observaram um efeito sazonal sobre a resistência do bovino ao carrapato, a qual, diminuiu no outono e aumentou na primavera e, Sutherst et al. (1983), propuseram que a causa primária da perda sazonal da resistência ao $B$. microplus durante o período de inverno, foi a diminuição da resposta fisiológica do hospedeiro a um fotoperíodo diminuído e que o estresse nutricional acentuou a perda da resistência e retardou a sua recuperação. É notório que a perda da resistência dos animais aos parasitos em geral, tem estado associada à má

Tabela 3. Médias mensais do número de carrapatos*, considerando-se os diferentes graus de mestiçagem dos animais $^{\star *}($ set/88 a ago/89)

\begin{tabular}{lccccccccccccc}
\hline & set & out & nov & dez & jan & fev & mar & abr & mai & jun & jul & ago & D.M.S. $^{* \star *}$ \\
\hline Grupo I & 5.14 & 2.56 & 2.96 & 2.54 & 2.73 & 2.93 & 2.66 & 3.71 & 5.12 & 5.43 & 6.28 & 4.76 & 1.95 \\
Grupo II & 5.94 & 3.00 & 3.41 & 3.44 & 3.25 & 3.68 & 3.24 & 4.01 & 5.95 & 6.09 & 7.79 & 6.08 & 4.86 \\
Grupo III & 5.34 & 2.67 & 3.08 & 2.77 & 2.86 & 3.12 & 2.80 & 3.78 & 5.33 & 5.59 & 6.66 & 5.09 & 1.78 \\
\hline
\end{tabular}

*Os valores representados na tabela foram transformados por $\sqrt{x+0,5}$

**Grupo I - animais com características fenotípicas consagradas do zebu

Grupo II - animais com características fenotípicas incompletas do zebu

Grupo III - reunião dos dois grupos acima

** DMS obtido pelo teste de Tukey a $5 \%$ de probabilidade 
nutrição. No caso da infestação por B. microplus, O'Kelly \& Seifert (1969), observaram que o nível de resistência ao carrapato fói estável diante de uma dieta adequada e que sua deficiência influenciou na queda da resistência. O marcado efeito da nutrição sobre a resistência ao $B$. microplus, ainda foi verificado por O'Kelly \& Seifert (1970) e Sutherst et al. (1983).

Assim sendo, o aumento no número de carrapatos durante o inverno, na região estudada, pode ter ocorrido em razão de uma diminuição da resistência dos animais, talvez para a fixação de larvas (Sutherst et al., 1973), em virtude da deficiência alimentar, ou ainda, em consequência de condições climáticas mais favoráveis para o desenvolvimento embrionário e larval do B. microplus, principalmente, a temperatura média, mais amena neste período ou ainda, um somatório desses fatores. Porquanto, se faz necessário garantir a alimentação suplementar adequada, em níveis suficientes, durante o inverno, para animais em regime de pastagem semelhante, a fim de se evitar o efeito deletério do carrapato.

\section{Abstract \\ Susceptibility of Zebu X European crossbred cattle to Boophilus microplus (Canestrini, 1887) in the region Fluminense do Grande Rio, State of Rio de Janeiro}

Twenty four calves cross-bred (Bos indicus $\times B$. taurus) of both sexes and approximately nine months old were assorted in there groups. Group I comprised eighteen calves with typical zebu phenotype. Group II and group III were, respectively, consisted of six cross-bred calves without typical zebu phenotypes and all calves in the experiment. All calves were kept in Boophilus microplus infested pastures during the experimental period of one year, from Sept/88 to Aug/89. Tick numbers were assessed by counting all engorged females lenghtier than $4,5 \mathrm{~mm}$. Ticks were present throughout the year by infestation burdens was higher from May to September. Tick burdens were higher in group $I /$ in comparasion to group I.

Key words: ticks, Boophilus microplus, bovine, cross-bred

\section{Referências Bibliográficas}

AYCARDI, E., BENAVIDES, E., GARCIA, O., MATEUS, G., HENAO, F., ZULUAGA, F. N. Boophilus microplus Tick Burdens on Grazing Cattle in Colombia. Trop. Ani. Health Prod., v. 16, p. 78-84, 1984

GOMES, F. P. Curso de Estatística Experimental. 11 ed. Piracicaba: Nobel, 1985. $466 \mathrm{p}$.

JOHNSTON, L. A. Y. Epidemiology of Bovine Babesiosis in Northern Qeensland. Aust. Vet. J., v. 43, p. 427-432, 1967.

KELLEY, R. B. Zebu Cross Cattle in Northern Australia. An Ecological Experiment. Bull. Coun. Sci. Industr. Res., Melbourne, n. 172, 1943.

MADALENA, F. E., TEODORO, R. L., LEMOS, A. M., OLIVEIRA, G. P. Causes of Variation of Fieldburdens of Cattle Ticks (Boophilus microplus). Rev. Bras. Gen., v. 8, p. 361-175, 1985.

O'KELLY, J. C., SEIFERT, G. W. Relationships Between Resistance to Boophilus microplus, Nutrutional Status, and Blood Composition in Shorthon x Hereford Cattle. Aust. J. Biol. Sci., v. 22, p. 1497-1506, 1969.

O'KELLY, J. C., SEIFERT, G. W. The Effects of Tick (Boophilus microplus) Infestations on the Blood Composition of Shorthorn $x$ Hereford Cattle on High and Low Planes of Nutrition. Aust. J. Biol. Sci., v. 23, p. 681-690, 1970.

PENNA, V. M. Boophilus microplus: a Resistência Genética do Hospedeiro Como Forma de Controle. Cad. Téc. Esc. Vet. UFMG, Belo Horizonte, v. 4, p. 3-65, 1990.

SEIFERT, G. W. Variations Between and Within Breeds of Cattle in Resistance to Field Infestations of the Cattle Tick (Boophilus microplus). Aust. J. Agric. Res., v. 22, p. 159-168, 1971.

SUTHERST, R. W., UTECH, K. B. W. Controlling Livestock Parasites with Host Resistance. In: Pimentel, D. (Ed.), Handbook of Pest Management in Agriculture. Florida, CRC Press, 1982. v. 2, p. 385-405.

SUTHERST, R. W., UTECH, K. B. W., DALLWITZ, M. J., KERR, J. D. Intraspecific Competition of Boophilus microplus (Canestrinni) on Cattle. J. Appl. Ecol., v. 10, p. 855-862, 1973.

SUTHERST, R. W., KERR, J.D., MAYWALD, G. F., STEGEMAN, D. A. The Effect of Season and Nutrition on the Resistance of Cattle to the Tick Boophilus microplus. Aust. J. Agric. Res., v. 34, p. 329-339, 1983.

SUTHERST, R. W., MAYWALD, G. F., BOURNE, A. S., SUTHERLAND, I. D. STEGEMAN, D. A. Ecology of the Cattle Tick (Boophilus microplus) in subtropical Australia. II. Resistance of Different Breeds of Cattle. Aust. J. Agric. Res., v. 39, p. 299-308, 1988.

VILLARES, J. B. Climatologia Zootécnica. III. Contribuição ao Estudo da Resistência e Susceptibilidade Genética dos Bovinos ao Boophilus microplus. Bol. Industr. Anim., v. 4, p. 60-80, 1941

WHARTON, R. H., UTECH, K. B. W. The Relation Between Engorgement and Dropping of Boophilus microplus (Canestrini) (Ixodidea) to the Assessment of Tick Numbers on Cattle. J. Aust. Entomol. Soc., v. 9; p. 171- 182, 1970. 